\title{
Research of Financial Support on Innovative Elements Concentration and High-Quality Innovative Development
}

\author{
Ping $\mathrm{He}^{1}$ and Jianming Zhou ${ }^{1, *}$

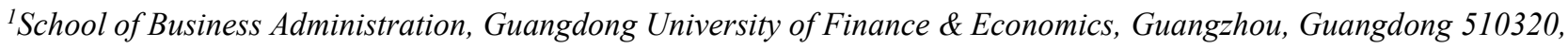 \\ China \\ *Corresponding author. Email: jmzhou@gdufe.edu.cn
}

\begin{abstract}
The study aims to study how financial support affects high-quality innovative development of artificial intelligence (AI) small and medium-sized enterprises (SMEs) through promoting innovative elements concentration, and takes 122 CEOs from 122 AI SMEs in Southern China as empirical studied samples. With the analysis of structural equational modelling, the research results showed that financial support including both policy-based financial support and market-based financial support had direct positive impact on innovative elements concentration and high-quality innovative development of AI SMEs. Moreover, innovative elements concentration had a direct positive impact on high-quality innovative development of AI SMEs significantly, and meanwhile mediated the relationship between policy-based financial support and high-quality innovative development of AI SMEs and the relationship between market-based financial support and high-quality innovative development of AI SMEs.
\end{abstract}

Keywords: financial support, innovative elements concentration, high-quality innovative development,

artificial intelligence

\section{INTRODUCTION}

With the inclination of national policies and the development of related basic technologies such as $5 \mathrm{G}$, China's artificial intelligence (AI) industry has entered an explosive growth stage (Ning, 2021)[1]. According to the "2021 AI Development White Paper", in 2020, the scale of China's core AI industry will reach 325.1 billion Yuan, increase of $16.7 \%$, making it the second largest industrial market in the world after the United States [2]. With the rapid development of China's AI industry, the competition among Chinese AI enterprises has become increasingly fierce. At the end of 2020, the number of AI related enterprises in China has reached more than 6,000. Among them, $22.3 \%$ are located at the basic layer of the AI industry chain, $18.6 \%$ are located at the technology layer, and $59.1 \%$ are located at the application layer [2]. Li (1998) [3] pointed out that innovation development was an important means for enterprises to gain competitiveness and survive the competition. Therefore, high-quality innovative development has become an important measurement indicator for deciding whether Chinese small and medium-sized enterprises (SMEs) can survive fierce competition and develop rapidly.

Wang and $\mathrm{Xu}$ (2012) [4] believed that high-quality innovative development cannot be separated from the support of finance, and only enterprises that had the financial support can go further on the path of innovation. The "2021 AI Development White Paper" showed that with the explosive development of Chinese AI market, the amount of Chinese AI field financial support had reached 89.62 billion Yuan in 2020, with a single maximum of 190 million Yuan [2]. Meanwhile, Wang (2020) [5] pointed out that financial support included policy-based financial support and market-based financial support. In other words, financial support including policy-based financial support and market-based financial support may be an important factor for promoting AI enterprises' high-quality innovative development.

In addition, Liu (2010) [6] pointed out that strengthening scientific and technological financial cooperation can help guiding and supporting the accumulation of innovative elements concentration, thereby promoting the high-quality innovative development of enterprises. In other words, the reason why financial support including policy-based financial support and market-based financial support can promote the high-quality innovative development of AI SMEs is likely to be achieved through the intermediary variable of innovative elements concentration.

However, most previous studies on the high-quality innovation development of AI SMEs were based on the perspective of technology development and technology research such as AI application scenarios (Wang and $\mathrm{Li}$, 2008) [7], AI technology implementation (Steve, 2018) [8], and basic AI algorithms (Mundici, 2021) [9]. Few studies have been conducted from the perspectives of financial 
management and the concentration of innovative elements. From theory to empirical research, there are few discussions on studying the relationship among financial support, innovative elements concentration, and the highquality innovative development of AI SMEs.

Therefore, this study would like to take 122 CEOs from 122 Chinese AI enterprises in Southern China as the empirical study samples, so as to find out whether and how financial support including policy-based financial support and market-based financial support can help increasing high-quality innovative development of AI SMEs through promoting innovative elements concentration, thereby to provide new suggestions for AI enterprises to develop AI related high-quality innovative product while meeting the need of customer satisfaction.

\section{RESEARCH DESIGN}

\subsection{Research Framework}

Summarizing the previous study of the research purpose, we provide hypotheses below, and provide the theoretical framework in Fig. 1.

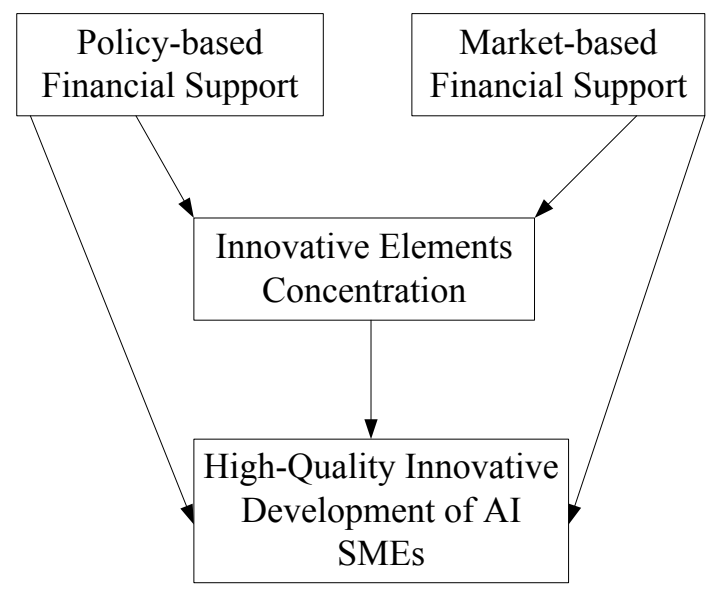

Figure 1. Research framework

H1a: Policy-based financial support has a direct positive effect on high-quality innovative development of AI SMEs significantly.

H1b: Market-based financial support has a direct positive effect on high-quality innovative development of AI SMEs significantly.

H2a: Policy-based financial support has a direct positive effect on innovative elements concentration significantly.

H2b: Market-based financial support has a direct positive effect on innovative elements concentration significantly.
H3: Innovative elements concentration has a direct positive effect on high-quality innovative development of AI SMEs significantly.

$\mathrm{H} 4 \mathrm{a}$ : Innovative elements concentration mediates the relationship between policy-based financial support and high-quality innovative development of AI SMEs significantly.

$\mathrm{H} 4 \mathrm{~b}$ : Innovative elements concentration mediates the relationship between market-based financial support and high-quality innovative development of AI SMEs significantly.

\subsection{Measuring Scales}

Five-point Likert scales were used to test all the studied variables in the paper including policy-based financial support (PFS), market-based financial support (MFS), innovative elements concentration (IEC), and high-quality innovative development of AI SMEs (HID). The measuring scale for financial support including two dimensions of policy-based financial support and market-based financial support was developed from Wang (2020) [5] which contained 3 items for each dimension. The measuring scale for innovative elements concentration was developed from Xiao (2020) [10] which contained 4 items. And the measuring scale for high-quality innovative development of AI SMEs was developed from Fu et al. (2021) [11] which contained 3 items.

\subsection{Research Samples}

The questionnaires were mainly answered by AI Company CEOs from two first-line Cities in Southern China. With the assistance of the local government, we issued a total of 150 questionnaires within three months, and finally recovered 145. After eliminating 23 questionnaires with missing data and obvious data logic errors, 122 questionnaires were finally obtained for data analysis. Through the descriptive statistical analysis of SPSS19.0, it is found that there are 91 male CEOs, taking accounting of $75 \%$, and 31 female CEOs, taking account of $25 \% ; 41$ CEOs with PHD degrees, taking accounting of $34 \%, 55$ CEOs with master's degrees, taking accounting of $45 \%$, and 26 CEOs with bachelor's degrees or below, taking accounting of $21 \%$.

\section{DATA ANALYSIS}

\subsection{Reliability and Validity Test}

In order to ensure the reliability of the measuring scale of policy-based financial support, market-based financial support, innovative elements concentration, and highquality innovative development of AI SMEs, we used 
SPSS19.0 to conduct Cronbach's $\alpha$ test. Results in Table 1 showed that all the Cronbach's $\alpha$ value of variables were higher than 0.7 , ranging from 0.80 to 0.88 , indicating that all the measuring scale had good reliability.

And the validity test of policy-based financial support, market-based financial support, innovative elements concentration, and high-quality innovative development of AI SMEs was used confirmative factor analysis (CFA) method. The average variance extracted (AVE) and composite reliability (CR) value of variables in Table 1 were higher than 0.5 and 0.7 respectively8, indicating that all the measuring scale had good convergent validity. Moreover, the results in Table 2 suggested that all the scales had good discriminative validity.

\subsection{Theoretical Model Test}

Zhou et al. (2020) [12] believes that the theoretical model analyzed by structural equational modelling (SEM) should considering 3 aspects indexes including absolute index fit, asymptotic index fit, and the summarized index fit. Therefore, after establishing direct and indirect SEM to test the verification, the fitting index results were shown in Table 3 as below. It found that most indexes met the acceptable standard requirements, which suggested that both the direct and indirect SEM were acceptable.

\subsection{Hypothesis Test}

To sum up the results from direct and indirect SEM, we presented the hypotheses tested results in Table 4 and found that hypotheses from $\mathrm{H} 1 \mathrm{a}$ to $\mathrm{H} 3$ were all getting supported.

The direct and indirect SEMs with coefficients were presented in Fig. 2 and Fig. 3.

Table 1. Cronbach's $\alpha$ Value of Studied Variables

\begin{tabular}{|c|c|c|c|c|c|}
\hline Variables & Items & $\alpha$ if item deleted & Cronbach's $\alpha$ & AVE & $\mathbf{C R}$ \\
\hline \multirow{3}{*}{ Policy-Based Financial Support } & PFS1 & 0.80 & \multirow{3}{*}{0.86} & \multirow{3}{*}{0.68} & \multirow{3}{*}{0.87} \\
\hline & PFS2 & 0.77 & & & \\
\hline & PFS3 & 0.85 & & & \\
\hline \multirow{3}{*}{ Market-Based Financial Support } & MFS1 & 0.80 & \multirow{3}{*}{0.87} & \multirow{3}{*}{0.69} & \multirow{3}{*}{0.87} \\
\hline & MFS2 & 0.79 & & & \\
\hline & MFS3 & 0.85 & & & \\
\hline \multirow{4}{*}{ Innovative Elements Concentration } & IEC1 & 0.87 & \multirow{4}{*}{0.88} & \multirow{4}{*}{0.65} & \multirow{4}{*}{0.88} \\
\hline & IEC2 & 0.84 & & & \\
\hline & IEC3 & 0.84 & & & \\
\hline & IEC4 & 0.83 & & & \\
\hline \multirow{3}{*}{$\begin{array}{c}\text { High-Quality Innovative Development of } \\
\text { AI SMEs }\end{array}$} & HID1 & 0.70 & \multirow{3}{*}{0.80} & \multirow{3}{*}{0.58} & \multirow{3}{*}{0.81} \\
\hline & HID2 & 0.74 & & & \\
\hline & HID3 & 0.74 & & & \\
\hline \multicolumn{2}{|l|}{ Standard } & $>0.50$ & $>0.70$ & $>0.50$ & $>0.70$ \\
\hline
\end{tabular}

Table 2. CFA Tested Results

\begin{tabular}{|c|c|c|c|c|c|}
\hline Model & Variables & RMSEA & TLI & CFI & $\boldsymbol{\chi 2} / \mathbf{d f}$ \\
\hline Four-factor & PFS, MFS, IEC, HID & 0.089 & 0.927 & 0.944 & 1.966 \\
\hline Three-factor -1 & PFS+MFS, IEC, HID & 0.125 & 0.855 & 0.885 & 2.904 \\
\hline Three-factor -2 & PFS, MFS+IEC, HID & 0.160 & 0.765 & 0.814 & 4.087 \\
\hline Three-factor -3 & PFS, MFS+HID, IEC & 0.156 & 0.778 & 0.823 & 3.929 \\
\hline One-factor & PFS+MFS+IEC+HID & 0.192 & 0.661 & 0.718 & 5.456 \\
\hline Requirement & $/$ & $<0.1$ & $>0.8$ & $>0.8$ & $1 \sim 3$ \\
\hline
\end{tabular}


Table 3. Fitting Indexes of Direct and Indirect SEM

\begin{tabular}{|c|c|c|c|c|c|}
\hline \multicolumn{2}{|c|}{ Indexes } & Perfect standard & $\begin{array}{l}\text { Acceptable } \\
\text { standard }\end{array}$ & Direct SEM & $\begin{array}{c}\text { Indirect } \\
\text { SEM }\end{array}$ \\
\hline \multirow{3}{*}{$\begin{array}{l}\text { Absolute } \\
\text { index fit }\end{array}$} & GFI & Higher than 0.90 & Higher than 0.80 & 0.938 & 0.881 \\
\hline & RMR & Lower than 0.05 & Lower than 0.08 & 0.039 & 0.058 \\
\hline & RMSEA & Lower than 0.08 & Lower than 0.10 & 0.066 & 0.089 \\
\hline \multirow{4}{*}{$\begin{array}{l}\text { Asymptotic } \\
\text { index fit }\end{array}$} & AGFI & Higher than 0.90 & Higher than 0.80 & 0.883 & 0.816 \\
\hline & RFI & Higher than 0.90 & Higher than 0.80 & 0.911 & 0.861 \\
\hline & NFI & Higher than 0.90 & Higher than 0.80 & 0.941 & 0.895 \\
\hline & CFI & Higher than 0.90 & Higher than 0.80 & 0.978 & 0.944 \\
\hline \multirow{4}{*}{$\begin{array}{l}\text { Summarized } \\
\text { index fit }\end{array}$} & $\chi 2 / \mathrm{df}$ & From 1.00 to 2.00 & From 2.00 to 3.00 & 1.523 & 1.966 \\
\hline & PNFI & Higher than 0.50 & Higher than 0.50 & 0.627 & 0.677 \\
\hline & PGFI & Higher than 0.50 & Higher than 0.50 & 0.500 & 0.571 \\
\hline & AIC & $\begin{array}{c}\text { Lower than Satu. } \\
\text { AIC (182) }\end{array}$ & $\begin{array}{l}\text { Lower than Indp. } \\
\text { AIC (1131) }\end{array}$ & 78.548 & 180.001 \\
\hline
\end{tabular}

Table 4. The Hypothesis Tested Results

\begin{tabular}{|c|l|c|c|c|}
\hline Route & \multicolumn{1}{|c|}{ Coefficients } & P-value & Hyp. & Results \\
\hline PFS $\rightarrow$ HID & $0.307^{*}$ & 0.039 & H1a & Yes \\
\hline MFS $\rightarrow$ HID & $0.384^{*}$ & 0.011 & H1b & Yes \\
\hline PFS $\rightarrow$ IEC & $0.361^{*}$ & 0.013 & H2a & Yes \\
\hline MFS $\rightarrow$ IEC & $0.291^{*}$ & 0.042 & H $2 \mathrm{~b}$ & Yes \\
\hline IEC $\rightarrow$ HID & $0.969^{* * *}$ & 0.000 & H3 & Note: $* \mathrm{P}<0.05 ; * * P<0.01 ; * * * 00.001$
\end{tabular}

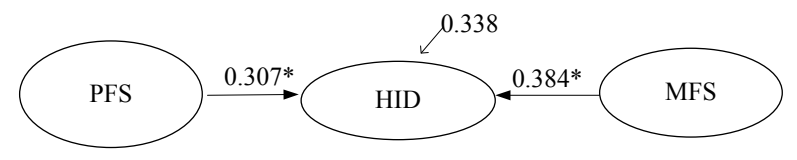

Figure 2. The Direct SEM with Coefficients

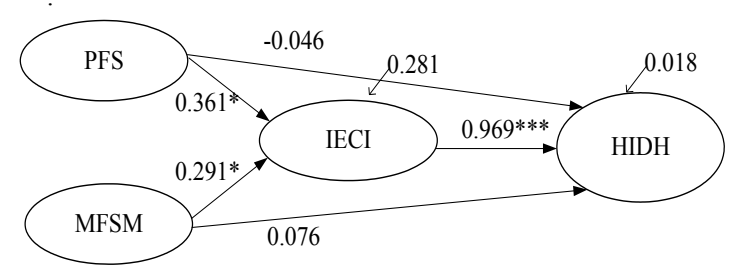

Figure 3. The Indirect SEM with Coefficients

Moreover, the results in Fig. 2 and Fig. 3 showed that when the direct SEM was added with innovative elements concentration, the direct effect of financial support including both policy-based financial support and marketbased financial support on high-quality innovative development of AI SMEs became insignificant. According to the theory of Baron and Kenny (1986) [13], it suggested that innovative elements concentration was likely to play mediating role between financial support including both policy-based financial support and market-based financial support on high-quality innovative development.

Therefore, we used bootstrapping methods provided by Hayes (2013) [14] to make further test. Bootstrapping results showed that the indirect effect of IEC on PFS to HID and indirect effect of IEC on MFS to HID were 0.361 and 0.383 , between $95 \%$ confident interval of $[0.265$, $0.472]$ and [0.262, 0.517], which included no zero. It indicated that the mediating effect of IEC on PFS to HID and IEC on MFS to HID were significant. Therefore, H4a and $\mathrm{H} 4 \mathrm{~b}$ are getting supported.

\section{CONCLUSION}

The study examined whether and how financial support including policy-based financial support, market-based financial support financial support affecting high-quality innovative development of AI SMEs through promoting innovative elements concentration with 122 CEOs from 122 AI enterprises in Southern China as empirical study samples. It was found that financial support including both policy-based financial support and market-based financial support had direct positive impact on innovative elements concentration and high-quality innovative development of AI SMEs. Moreover, innovative elements concentration had direct positive impact on high-quality innovative 
development of AI SMEs significantly, and mediated the relationship between policy-based financial support and high-quality innovative development of AI SMEs, as well as the relationship between market-based financial support and high-quality innovative development of AI SMEs.

These conclusions have theoretical and practical contributions to the theories of financial support, innovation management and AI High-quality innovative development. The results of this paper find that to promote the high-quality innovative development of AI SMEs, every effort should be made to obtain technological financial support, including policy-based financial support and market-based financial support. With financial support, it can speed up the rapid gathering of innovative elements such as AI industry talents, technology, and information to $\mathrm{AI}$ enterprises. This allows AI enterprises to reserve more R\&D personnel and master more AI cutting-edge technologies, thereby developing higher-quality innovative AI products, thus occupying a favourable position in the AI international market competition.

\section{ACKNOWLEDGMENTS}

This work was supported by Guangdong Provincial Soft Science Project (Grant No.2020A1010020045), National Statistical Science Project of the National Bureau of Statistics (Grant No.2020LY104), and the 13th five-year Plan of Education and Scientific Research in Guangdong Province (Grant NO.2020GXJK114).

\section{REFERENCES}

[1] S.J. Ning, "The integration and development trend of $5 \mathrm{G}$ communication technology and artificial intelligence," China Broadb. Beijing, vol. 16, pp. 1-2, August 2021.

[2] Shenzhen AI Association, The Whit Book on the Development of Artificial Intelligence in 2021, Unpublish, 2021.

[3] T.Z. Li, "Innovative development and competitiveness: decision-making strategy," Manage. Obser. Beijing, vol. 17, pp. 42-43, April 1998. DOI: https:/CNKI:SUN:GLKW.0.1998-04-195

[4] H.Q. Wang, Y.L. Xu, “A measure model for synergy degree between Sci-tech innovation and Sci-tech finance and its application," China Soft Sci. Beijing, vol. 26, pp. 129-138. DOI: https://10.3969/j.issn.10029753.2012.06.015

[5] W.J. Wang, Research on the Impact of Financial Support on the Efficiency of Agricultural Technology Innovation. Huazhong Agricultural University, 2020.
[6] Z.Y. Liu, "Thoughts on promoting independent innovation by Sci-tech financial cooperation," Anhui Sci. and Tech. Hefei, vol. 22, pp. 17-19, August 2010. DOI: https://10.3969/j.issn.1007-7855.2010.08.009

[7] H.F. Wang, F. Li, "New progress in the application of artificial intelligence to education," Modern Edu. Tech. Beijing, vol 18, pp. 18-20, December 2008. DOI: https://CNKI:SUN:XJJS.0.2008-S1-010

[8] M. Steve, "The new generation of artificial intelligence hardware requires flexibility and programmability," Electro. Prod. Beijing, vol. 25, pp. 23, May 2018. DOI: https://CNKI:SUN:DZJR.0.201805-005

[9] D. Mundici, “Deciding Koopman's qualitative probability," Artif. Intelli. Amsterdam, vol. 299, pp. 103524, October 2021. DOI:

https://doi.org/10.1016/j.artint.2021.103524

[10] T. Xiao, Research on the Influence of Innovation Factors Agglomeration on Regional Innovation Efficiency. Shenzhen University, 2020.

[11] W.Y. Fu, Y. Li, Z.X. He, "Research on the impact of artificial intelligence on regional innovation and development," J. Indu. Tech. Eco. Changchun, vol. 40, pp. 51-57, November 2021.

[12] J.M. Zhou, Y. Liu, P. Zheng, “Artificial intelligence knowledge transfer and artificial intelligence new product development quality under knowledge leadership," Adv. in Intel. Sys. \& Comput. New York, vol. 1146, pp. 783-791, March 2020. DOI: https://10.1007/978-3-030-43306-2_110

[13] R.M. Baron, D.A. Kenny, “The moderatormediator variable distinction in social psychological research: Conceptual, strategic, and statistical considerations," J. Perso. \& Soc. Psy. Washington, vol. 51, pp. 1173-1182, December 1986. DOI: https://10.5859/kais.2012.21.1.47

[14] A.F. Hayes, An Introduction to Mediation, Moderation and Conditional Process Analysis: A Regression-based Approach, Guilford Press, New York, 2013. 